\title{
Alkaloid and polyphenolic profiles of Brazilian Uncaria tomentosta leaves
}

\author{
DS Pereira $\underline{\mathbf{1}} \underline{\mathbf{2}}, \operatorname{MDS}$ Geraldo $\underline{\mathbf{2}}$, AC Siani $\underline{\mathbf{1}}$, JBF Tostes $\underline{\mathbf{1}}$, JL Mazzei $\underline{\mathbf{1}}$, LMM Valente $\underline{\mathbf{3}}$
}

\footnotetext{
${ }^{1}$ Departamento de Produtos Naturais, Instituto de Tecnologia em Fármacos, Fundação Oswaldo Cruz, Rua Sizenando Nabuco 100, 21041 - 250, Rio de Janeiro, Brazil

${ }^{2}$ Departamento de Química, Campus de Gualtar, Universidade do Minho, 470 - 057, Braga, Portugal

${ }^{3}$ Instituto de Química, Universidade Federal do Rio de Janeiro, Departamento de Química Orgânica, Av. Athos da Silveira Ramos 149, Cidade Universitária, 21941 - 909, Rio de Janeiro, Brazil
}

Congress Abstract

The leaf alkaloidal and polyphenolic profiles from four wild Uncaria tomentosa (Willd.) DC specimens (cat's claw), harvested in different locations of the Brazilian Amazon rainforest have been analyzed. Methanol leaf extracts were treated with $\mathrm{HCl} 0.1 \mathrm{~N}$ followed by partition with ethyl acetate to afford phenol-rich fractions. The aqueous fractions were then alkalinized with $\mathrm{NH}_{4} \mathrm{OH}$ and extracted with ethyl acetate to afford alkaloid fractions. The alkaloid fractions from three specimens showed similar HPLC-DAD profiles, with the pentacyclic oxindole alkaloids mitraphylline and isomytraphylline predominating [1]. The fourth specimen showed a distinct profile with tetracyclic oxindole alkaloids as major components as revealed by $\left[\mathrm{M}^{+} \mathrm{H}\right]^{+}$ions at $\mathrm{m} / \mathrm{z} 385$ in UHPLC-MS, corroborated by diagnostic signals in ${ }^{1} \mathrm{H}-\mathrm{NMR}$. Apart from the sample with a distinct alkaloidal chemotype no significant differences occurred in the phenol-rich fraction profiles revealed by TLC and HPLCDAD. They contain mostly phenolic acid derivatives complemented by minor flavonoids. The common signal for chlorogenic acid was quantified in these phenol-rich fractions by comparison with an external standard, enabling evaluation of the linearity, detection limit and recovery. The chlorogenic acid content varied from 0.15 \pm 0.01 to $0.58 \pm 0.02 \mathrm{mg} / \mathrm{g}$ of dry leaves as measured at $280 \mathrm{~nm}$, whereas the total phenolic content varied between $147 \pm 22$ and $632 \pm 58 \mu \mathrm{g} \mathrm{GAE} / \mathrm{g}$ by Folin-Ciocalteu. This study of the chemistry of the aerial parts of the species complements earlier studies most of which have been performed on commercial alkaloid-based roots and bark materials.

Keywords: Uncaria tomentosa, leaf total phenols, chlorogenic acid, oxindole alkaloids,

\section{References:}

[1] Pereira RCA, Valente LMM, Pinto JEBP, Bertolucci SKV, Bezerra GM, Alves FF, Santos PFP, Benevides PJC, Siani AC, Rosario SL, Mazzei JL, d'Avila LA, Gomes LNF, Aquino-Neto FR, Emmerick ICM, Carvalhaes SF. J Braz Chem Soc 19: 1193 - 1200 (2008). 